\title{
Doenças do álamo
}

\author{
Louise Larissa MAY-DE MiO \\ LILIAN AMORIM ${ }^{2}$
}

\section{RESUMO}

A cultura do álamo no Brasil, assim como no resto do mundo, enfrenta sérios desafios em relação a pragas e doenças. No que se refere a doenças, a ferrugem das folhas, causada por Melampsora medusae, é a mais importante da cultura. A doença provoca pústulas nas folhas, aonde são produzidos urediniósporos em grande número, responsáveis pela disseminação, podendo ocasionar epidemias no verão. Com o avanço da doença, a queda das folhas é antecipada, interferindo no crescimento da árvore e armazenamento de energia para o próximo ciclo. Além da ferrugem, outras manchas foliares como as causadas por Septoria, Alternaria tenuis e Colletotrichum gloeosporioides já foram detectadas no Brasil. A mancha de Septoria é a mais importante pois o patógeno causa cancros nos galhos e tronco das árvores. Também são relatadas na literatura manchas foliares causadas por Marssonina spp, Taphrina spp e Venturia spp, além de diversos cancros e algumas podridões radiculares.

\section{ABSTRACT}

The poplar crop in Brazil, as in the rest of the world, has been attacked by a number of pests and diseases. The leaf rust, caused by Melampsora medusae is the most important disease. It causes pustules in leaves, which produces uredinospores in large quantities which spreads the disease causing epidemics in the summer time. After several cycles of the pathogen, the plant is early defoliated, grows poorly and retains less energy for the next year. Besides this disease, other leaf diseases caused by Septoria, Alternaria tenuis and Colletotrichum gloeosporioides have already been detected in Brazil. Leaf spot caused by $S$. musiva is the most important because the pathogen causes cankers in stems and branches. Other diseases have already been mentioned in different publications such as leaf spots caused by Marssonina spp, Taphrina spp, and Venturia spp, as well as several cankers and some root rot.

\footnotetext{
${ }^{1}$ Dep. Fitotecnia e Fitossanitarismo, SCA/UFPR

Rua dos Funcionários, 1540, 80.035.050, Curitiba-PR

e-mail:louisela@agrarias.ufpr.br

${ }^{2}$ Departamento de Entomologia, Fitopatologia e Zoologia Agrícola, ESALQ-USP,

C.P. 09, 13.418-900, Piracicaba-SP

e-mail:liamorim@carpa.ciagri.usp.br
} 


\section{INTRODUÇÃO}

Os plantios iniciais de álamo (Populus spp.) no Brasil ocorreram entre 1905 e 1910 com mudas provenientes dos EUA no município de Curitiba - PR. A principal espécie introduzida foi Populus deltoides var. carolinensis que naquela ocasião foi também enviada para a cidade de Caieiras no Estado de São Paulo. Em 1959, chegaram ao Brasil os primeiros clones da Argentina e Itália e, até 1960, atingiu-se uma área de 300 ha plantados. A cultura, no entanto, teve problemas de adaptação na região devido às exigências climáticas e, só a partir de 1980, quando surgiram novas técnicas e clones mais adaptados à região, empresas fabricantes de palito de fósforo interessaram-se em cultivar esta espécie. A partir de 1991 foram então implantados os primeiros viveiros que deram origem aos plantios definitivos com finalidade comercial.

O plantio comercial do álamo está sendo realizado no vale do IguaçúPR, com um total de aproximadamente 3.000 ha. Apesar do excelente crescimento e adaptação às condições daquele vale, os novos clones são extremamente exigentes em tratos culturais e cuidados com sanidade. $\mathrm{O}$ álamo é uma espécie florestal que agrega alto valor econômico e sua madeira clara e resistente é utilizada, dentre outros fins, para fabricação de palito de fósforo e móveis.

Tanto no Brasil, como no resto do mundo, a cultura enfrenta sérios desafios em relação a pragas e doenças. No que se refere à doença, vários os relatos de diferentes patógenos na literatura mundial.

\section{MANCHAS FOLIARES}

\section{I.1 FERRUGEM DO ÁLAMO - Melampsora spp.}

Melampsora spp. é o agente causal da ferrugem da folha do álamo, freqüentemente encontrado em clones suscetíveis durante os meses de ápice de crescimento da planta, de novembro a fevereiro. A doença provoca pústulas nas folhas, aonde são produzidos urediniósporos em grande número, responsáveis pela disseminação, podendo ocasionar epidemias no verão. Com o avanço da doença, após vários ciclos consecutivos do patógeno, a queda das folhas que normalmente ocorre em meados do outono é antecipada, interferindo no crescimento da árvore e armazenamento de energia para o próximo ciclo.

Quando a doença quanto atinge níveis epidêmicos, pode causar sérios danos à cultura. WIDIN \& SCHIPPER JR (1981) observaram perdas de 65\% no volume de árvores devido à alta incidência de $M$. medusae em $P$. deltoides No vale do rio Iguaçu (PR), região do plantio de álamo no Brasil, clones suscetíveis infectados com ferrugem, tiveram sua produção de madeira reduzida em até 3 vezes quando comparados com plantas tratadas com fungicidas (MAY DE MIO, 1997; MAY DE MIO \& SCHUTA, 1997). 
Importância da doença, sintomatologia e danos: a ferrugem do álamo, ocasionada por Melampsora medusae, destaca-se como o principal problema fitossanitário da cultura no viveiro (WALKER, 1975), pois reduz a área fotossintetizante, provoca queda antecipada das folhas e redução na produção de madeira (WALKER, 1975; SHAIN \& CORNELIUS, 1979), causando perdas para o produtor (SHERIDAN, 1981).

Vários trabalhos relatam a importância da ferrugem do álamo em outros países, porém no Brasil pouco se sabe sobre o comportamento dessa doença. VIÉGAS, em 1945, relatou a ocorrência de M. medusae em Populus spp. nos Estados de Minas Gerais, São Paulo e Rio Grande do Sul. No Paraná, NOVACKI \& FONTOURA (1968) observaram um intenso ataque da ferrugem (Melampsora spp.) em Populus deltoides var. carolinensis. No entanto, naquela ocasião, não foi identificada a espécie do patógeno. RUARO \& MAY (1996) identificaram a espécie que ocorre no Paraná de acordo com dados morfológicos dos urediniósporos (tamanho médio de urediniósporos de 20 - 38 x $13-21 \mu \mathrm{m}$ com formato abovalado a oval, ápice arredondado e base truncada com parede externa saliente) como Melampsora medusae Thüm, em concordância com a descrição da literatura (WALKER, 1975; TRENCH et al., 1988). Esta identificação foi também confirmada pelo Dr. Mário Barreto Figueredo do Instituto Biológico de São Paulo. Entretanto, para melhor elucidar o avanço da epidemia em clones que anteriormente se comportavam como resistentes, ainda faz-se necessária à identificação das raças do patógeno. Diversos trabalhos (CELLERINO, 1986; Alegro et al., 1992; GIORCELLI et al.,1994) relatam a ocorrência de ferrugem no álamo em outros países aonde as espécies Melampsora larici-populina Kleb e Melampsora alli-populina Kleb são as mais comuns. Nas nossas condições, nos plantios comerciais identificouse apenas Melampsora medusae Thüm.

Os sintomas são pústulas de coloração amarela a alaranjada que se distribuem pela superfície inferior e superior da folha. Em alguns casos, as pústulas se unem e formam posteriormente regiões necrosadas, levando à queda prematura das folhas. Os sintomas aparecem, geralmente, no final da primavera, progredindo até o final do verão quando se inicia o processo de desfolha natural. Esta desfolha contribui para um depauperamento da árvore, pois a queda antecipada das folhas impede que a planta armazene energia para passar o inverno e o resultado disto é notado no ano seguinte com acentuada perda de crescimento (PAILLASSA, 1996).

Esta espécie de fungo é predominante em clones puros ou híbridos de $P$. deltoides, sendo sua ocorrência de maior importância na Nova Zelândia, na Austrália e nos EUA (SPIERS, 1975; PRAKASH \& HEATHER, 1986B; MCCRACKEN et al. 1984; NEWCOMBE \& CHASTAGNER, 1993). Na Europa, principalmente na França, Bélgica e Itália predominam os clones 
chamados euroamericanos que são preferencialmente infectados por outra espécie de Melampsora, a M. larici-populina (PINON \&FREY, 1998).

Diferentes variedades de álamo estão sendo cultivadas no vale do Iguaçu. Algumas destas variedades são extremamente suscetíveis à ferrugem. Nos meses mais quentes do ano (dezembro a março), a doença provoca desfolha precoce, principalmente em mudas e árvores de 1 a 2 anos de idade, o que tem preocupado os produtores, pois algumas vezes, as variedades mais suscetíveis são também as mais promissoras em termos de produção e qualidade de madeira.

WILCOX \& FARMER (1967) observaram que a ferrugem tinha pouco efeito no crescimento da plantas de álamo na primeira fase de crescimento. No entanto, no ano seguinte à epidemia, o diâmetro e a altura da planta eram reduzidos. Outros autores também já verificaram que a infecção de Melampsora medusae provoca desfolha prematura e redução no crescimento (TOOLE, 1967; WIDIN \& SCHIPPER, 1976; COOPER \& FILER JR,1977; STEENACKERS et al., 1995). PAILLASSA (1996) descreveu que, em conseqüência da infecção, a atividade fotossintética é reduzida e isto resulta em uma diminuição do crescimento em diâmetro e altura, e em consequiência o volume de madeira produzido é menor. Também são constatadas alterações na qualidade da madeira e diminuição das substâncias de reservas armazenadas. Todo este prejuízo é tanto maior, quanto mais precoce for o ataque no ciclo de cultivo.

ESPÉCIES DE MELAMPSORA E VARIABILIDADE PATOGÊNICA: a ferrugem do álamo é causada por diferentes espécies e raças do gênero Melampsora. Na França, foram detectadas três espécies: M. larici-populina, $M$. allii-populina e $M$. medusae, $M$. larici-populina; tem seu nome relacionado aos seus hospedeiros: coníferas (larici) e álamo (populina); enquanto M. allipopulina tem como hospedeiro alternativo o alho (allii). M. medusae tem vários hospedeiros (mais de dois) e devido a este fato não existe analogia do nome latino com as plantas hospedeiras. A diferenciação entre as duas primeiras espécies é fácil, os teliósporos de M. larici-populina situam-se na face superior da folha e de M. allii populina na inferior (PAILLASSA, 1996). M. medusae é separada das demais espécies do gênero por possuir paráfises uniformes com ápices globosos e urediniósporos com falta de ornamentação em uma larga região equatorial do esporo (WALKER, 1975). Alguns autores classificam esta espécie como M. medusae f.sp. deltoides (SHAIN, 1988b) que é nativa do leste da América do Norte, com origem coincidente com o álamo do leste, Populus deltoides (NEWCOMBE \& CHASTAGNER, 1993). Este fato é coerente com a ocorrência de $M$. medusae no vale do Iguaçu, pois praticamente todos clones de álamo introduzidos no Brasil são $P$. deltoides puros ou híbridos.

Várias outras espécies de Melampsora são relatadas no mundo, causando problemas no álamo (Populus spp.): M. albertensis, $M$. 
caryophyllacearum, M. epige e M. abieti-capraearum. Entretanto, de acordo com NEWCOMBE \& CHASTAGNER (1993), pesquisadores dos EUA, a espécie M. medusae f.sp. deltoides é a mais disseminada.

Além das espécies já citadas, SPIERS \& HOPCROFT (1994), investigando as possíveis causas da quebra de resistência em cultivares na Nova Zelândia, identificaram uma ferrugem híbrida interespecífica de $M$. medusae e M. larici-populina. Este híbrido, segundo os autores, exibe características fisiológicas e ultraestruturais de ambos os pais. Foi, então, denominada como Melampsora medusae-populina sp.nov. Outro híbrido, encontrado na literatura, é Melampsora x columbiana, resultante da mistura de $M$. medusae com $M$. occidentalis (NEWCOMBE et al. 2000).

Apesar do grande número de espécies e de raças de Melampsora que afeta a cultura do álamo o controle através de cultivares resistentes é o método mais empregado nos países desenvolvidos (SINGH \& HEATHER, 1982; PRAKASH \& THIELGES, 1987; STEENACKERS ET AL. 1994; PAILLASSA, 1996).

CIClO DAS RELAÇÕES PATÓgENO-HOSPEDEIRO: o fungo do gênero Melampsora que causa ferrugem em álamo é macrocíclico e heteróico. Os hospedeiros alternativos são normalmente coníferas. Na primavera, os basidiósporos produzidos em folhas de álamo mortas e caídas no chão são disseminados pelo vento, penetram nas folhas do hospedeiro intermediário (por exemplo, acículas de coníferas) e produzem pícnios e, em seguida, aécios. Deste ponto em diante, formam-se os aeciósporos que são dispersos pelo vento até as folhas de álamo. Nesta etapa, formam-se os urediniósporos que são responsáveis pela epidemia durante os meses de verão. As folhas atacadas caem, e então, formam-se télios com teliósporos que passam o inverno em folhas mortas e dão origem aos basídios com basidiósporos para iniciar novamente o ciclo na primavera (WALKER, 1975). Nas nossas condições, no entanto, não se conhece hospedeiro alternativo e também não está bem esclarecido como o patógeno sobrevive durante o inverno visto que a planta perde totalmente as folhas.

Os hospedeiros alternativos reconhecidos na literatura internacional são: Larix laricina (DuRoi) K. Koch, Pseudotsuga menziesii (Mirb) Franco (ZILlER, 1974), Pinus banksiana Lamb e P. resinosa Ait (ZILLER, 1965). Em 1975, SPIERS reportou na Nova Zelândia várias espécies como hospedeiro aecial da ferrugem do álamo: Pinus radiata, Larix kaempferi e Larix decidua para M. larici-populina e para M. medusae, Larix decidua. Ainda hoje, alguns autores continuam pesquisando os hospedeiros alternativos desta ferrugem. SHAIN (1988a), testando várias espécies de coníferas, obteve sucesso apenas com a Larix decidua como hospedeira alternativa de M. medusae. 
EPIDEMIOLOGIA E CONTROLE: além do conhecimento do ciclo da ferrugem no campo, a influência de variáveis ambientais como temperatura e umidade no progresso da doença são fundamentais para o conhecimento do comportamento da epidemia em uma determinada região. Urediniósporos da espécie Melampsora medusae no baixo vale do Mississipi - EUA, germinam melhor a $18{ }^{\circ} \mathrm{C}$ e não germinam a $34{ }^{\circ} \mathrm{C}$ (TOOLE, 1967). Temperatura e precipitação podem influenciar o desenvolvimento da epidemia; temperaturas moderadas $\left(15-20^{\circ} \mathrm{C}\right)$ e chuvas abundantes aumentam a produção de esporos e freqüência de infecção (WIDIN \& SHIPPER Jr, 1980). O período latente para a infecção uredinial é de aproximadamente 8 dias sob condições de casa de vegetação e pústulas podem produzir urediniósporos maduros em 10 dias. McCRACKEN et al. (1984), avaliando urediniósporos coletados em armadilhas na mesma região, observaram que no ano de 1977 os urediniósporos apareceram em menor número e eram mais tardios quando comparados com o ano anterior, aonde foram registradas temperaturas moderadas e chuvas menos intensas.

PRAKASH \& THIELGES (1989), avaliando o efeito da temperatura sobre diferentes isolados de M. medusae, concluíram ser este fator de extrema importância na determinação do nível e tipo de expressão da doença na maioria das interações isolados/cultivares testadas. Anteriormente, em 1986, foi feito um estudo do efeito de regimes de temperatura na resistência de cultivares de álamo a raças de $M$. medusae e foram observadas diferenças de compatibilidade das raças em relação à temperatura (PRAKASH \& HEATHER, 1986b).

Além da temperatura, outros fatores como molhamento e precipitação são importantes para a epidemia. Em trabalho realizado nos EUA durante os anos de 1988 e 1989 , quando ocorreu uma epidemia severa ocasionada por $M$. medusae, HAMELIN et al. (1992) avaliaram a influência do molhamento, da temperatura e da chuva no desenvolvimento da doença a campo. Observaram que déficit de chuva e temperaturas altas não são fatores limitantes quando ocorrem condições ótimas de temperatura $\left(15-21^{\circ} \mathrm{C}\right)$ e molhamento $(10-12$ horas) para infecção durante a noite. Entretanto, WIDIN \& SCHIPPER Jr (1980) nos EUA e SHERIDAN et al. (1975) na Nova Zelândia observaram um aumento de urediniósporos capturados em armadilhas após chuvas intensas e maior incremento na taxa de desenvolvimento da ferrugem após chuva de 10 a 14 dias, respectivamente.

Em relação ao controle da ferrugem do álamo, sabe-se que o uso de variedades resistentes tem sido um dos métodos mais utilizados (ALEGRO et al., 1992). Em programas de melhoramento do álamo no Instituto de Florestas da Bélgica o principal critério para a seleção de genótipos das plantas é a resistência à ferrugem (STEENACKERS et. al., 1994).

PRAKASH \& HEATHER (1986b) estudaram a herança da resistência em diferentes raças de $M$. medusae e recentemente foi caracterizado um gene maior de resistência (Mmd1) para M. medusae f.sp. deltoides em híbrido de 
álamo na Universidade do Estado de Washington -EUA (NEWCOMBE et al., 1996). NEWCOMBE (1998), em trabalho posterior, verificou associação deste gene com variáveis quantitativas da ferrugem do álamo observando a contribuição de outros genes próximos ao $M m d 1$.

Outra forma de controle é o tratamento químico. De uma maneira geral, a utilização de controle químico é estabelecido levando-se em consideração o uso fungicidas indicados para os patógenos da cultura em outros países, como é o caso do uso de triadimenol no controle de Marssonina brunea (GIORCELLI \& VIETTO, 1992) e de triadimenol, tebuconazole e myclobutanil para espécies de Melampsora (GIORCELLI \& VIETTO, 1995). Trabalhos de PANDEY et al. (1996) mostraram a eficiência de triadimefon no controle de M. larici-populina em viveiro de álamo na Índia. SPIERS (1976) obteve sucesso no controle da mesma espécie, na Nova Zelândia, utilizando cobre, oxicarboxin e dodine e também verificou que o crescimento da raiz e do tronco era proporcional aos níveis de controle obtidos com o uso de fungicidas. No Brasil, trabalhos de MAY \& RUARO (1997) avaliaram a eficiência de fungicidas para controle da ferrugem em viveiro cujos resultados estão sumarizados na Tabela 1 .

Tabela 1 - Dosagem e fungicidas testados para o controle da ferrugem do álamo em viveiro, considerando uma calda de $300 \mathrm{~L} /$ ha aplicada com o canhão de pulverização (MAY \& RUARO, 1997).

p.c. $=$ produto comercial

\begin{tabular}{lc}
\hline Produtos & Dosagem recomendada para Álamo \\
\hline Captan & $250 \mathrm{ml}$ p.c./100L \\
Oxicloreto de Cobre & $600 \mathrm{~g} \mathrm{p.c./100 \textrm {L }}$ \\
Mancozeb & $1.5 \mathrm{~kg} \mathrm{p.c./100 \textrm {L }}$ \\
Cyproconazole & $125 \mathrm{ml}$ p.c./100L \\
Difenoconazole & $21 \mathrm{ml}$ p.c./100L \\
Oxicarboxin & $200 \mathrm{~g}$ p.c./100L \\
Tebuconazole & $250 \mathrm{ml}$ p.c./100L \\
Triadimenol & $250 \mathrm{ml}$ p.c./100L \\
\hline
\end{tabular}

O controle ideal é obtido com pulverizações iniciadas em meados de novembro com produtos de contato (mancozeb ou oxicloreto de cobre) e repetidas nos meses de janeiro e fevereiro com produtos sistêmicos (tebuconazole, cyproconazole, triadimenol e difenoconazole) intercalados com produtos de contato se o clima não estiver muito chuvoso. Os fungicidas sistêmicos do grupo dos inibidores da biossíntese do ergosterol são muito eficientes. No entanto é necessário o manejo correto destes produtos para evitar o aparecimento de resistência do fungo ao fungicida e manter prolongada a eficiência do controle químico. Se houver ocorrência de chuvas o ideal é intercalar produtos com diferentes ingredientes ativos sistêmicos a cada 20 ou 30 dias conforme a possibilidade. As aplicações devem ser feitas no início da manhã ou final da tarde, evitando o período mais quente do dia, adicionando-se 
espalhante adesivo à calda para melhorar a cobertura sobre as folhas especialmente com os produtos de contato.

\section{I.2 MANCHA FOLIAR DE SEPTORIA - Septoria populi}

Septoria causa manchas de folhas, reduzindo o crescimento das plantas pela queda prematura de folhas. Os corpos de frutificações infectam as folhas ou galhos durante o inverno. Na primavera, durante períodos de alta umidade, os esporos são lançados no ar. Eles infectam folhas novas. As primeiras manchas aparecem como uma mancha preta deprimida. Sob condições de umidade favorável, as manchas aumentam em tamanho. As manchas fundem-se nas folhas com infecções múltiplas e até $50 \%$ do tecido foliar pode ser afetado. Três ou quatro semanas após a infecção inicial surgem os picnídios, como pequenos pontos de cor preta no centro das lesões. Nesses picnídios são produzidos os conídios que disseminam a doença para outras árvores. Esporos produzidos nas folhas podem causar cancros em clones suscetíveis. O fungo sobrevive durante o inverno em folhas infectadas caídas e em cancros de ramos novos. Como controle desta doença deve-se manter o viveiro livre do patógeno e sempre que possível utilizar clones resistentes.

Esta doença já foi constatada no Brasil e os sintomas têm se agravado nos últimos anos. Em clones suscetíveis, a presença de cancros, mais evidenciados com a queda das folhas, tem preocupado os produtores.

\section{QUEIMA DAS FOLHAS - Alternaria tenuis}

MORRIS et al. (1975) relatam a ocorrência de Alternaria tenuis em álamo em países como Estados Unidos, Canadá e México. Essa doença é importante no viveiro e no campo. No Brasil, a doença tem ocorrido sem causar maiores preocupações.

Os esporos e o micélio do patógeno persistem de uma estação para outra nos restos de cultura no solo, disseminados pelos respingos de chuva e pelo vento, atingem as folhas novas e germinam dentro de 1 a 2 horas quando a umidade relativa é $100 \%$ e a temperatura entre 4,4 e $35^{\circ} \mathrm{C}$. A infecção se dá no tecido epidérmico de folhas jovens, com período latente de 5 a 7 dias (MORRIS et al., 1975). Nas faces superiores do limbo foliar, onde a doença tem sintomatologia típica, observam-se manchas de coloração cinza-claro, passando a cinza-escuro com sua evolução. As lesões são irregularmente circulares, algumas apresentando porção central esbranquiçada. Posteriormente, as lesões coalescem, formando uma área manchada com formato irregular.

\section{I.3 MANCHA FOLIAR DE MARSSONINA - Marssonina brunnea, $\mathrm{m}$.} populi, m. castagnei

Manchas foliares pequenas de formato angular aparecem na primavera e início do verão. Quando a severidade da doença é elevada, ocorre desfolha prematura e predisposição ao ataque de organismos secundários. O patógeno 
sobrevive nas lesões em ramos e em folhas infectadas caídas. Os conídios produzidos nas lesões são disseminados pela água, ocasionando infecções secundárias que desencadeiam a epidemia em meados para o final do verão. Também neste caso o controle indicado é o uso de clones resistentes além da sanitização, por meio da remoção do material infectado. Não há relato da ocorrência deste patógeno no Brasil.

\section{I.4 OUTROS PATÓGENOS CAUSADORES DE MANCHAS FOLIARES}

Diversos fungos causam doenças em folhas no álamo. Estas manchas foliares podem se tornar epidêmicas durante a primavera e verão úmido.

I.4.1 Antracnose - Colletotrichum gloeosporioides: as manchas começam nas bordas, proporcionando um aspecto de queima foliar, na maioria das vezes acompanhadas de um escurecimento de nervuras sendo mais claramente visível na página inferior. Quando as folhas são infectadas mais tardiamente, suas margens, e especialmente seus ápices, secam (MORRIS et al., 1975). As lesões podem ocorrer também nos pecíolos, sendo mais alongadas nesses órgãos. C. gloeosporioides sobrevive de uma estação para outra em restos de cultura e a doença é favorecida por condições de alta umidade e temperaturas amenas. No Brasil, o controle não tem sidonecessário devido à baixa intensidade e época de ocorrência (período de queda de folhas).

I.4.2 Crespeira - Taphrina populina, $T$. aurea, $T$. johansonii: doença de baixa frequiência, importante apenas em programas de melhoramento quando a produção de sementes é necessária. Os esporos são produzidos na superfície das folhas que se mostram deformadas (com áreas salientes semelhantes a bolhas). Há apenas um período de infecção por ano (OSTRY et al.1989).

I.4.3 Queima de folhas e brotos - Venturia macularis, V. populina, $V$. tremulae: o fungo ataca ramos e folhas que se tornam enegrecidos e distorcidos. $\mathrm{Na}$ primavera, aparecem áreas marrons a negras de formato irregular nas folhas. Brotos quebradiços e enegrecidos ficam curvados. Apenas brotos novos e folhas são suscetíveis, os tecidos maduros são resistentes. Como controle é indicada a utilização de clones resistentes. Além dos patógenos citados anteriormente, outros fungos tais como Cercospora populina, Phyllosticta sp, Ciborina spp, podem provocar manchas nas folhas., entretanto com ocorrência e danos menos freqüentes (OSTRY et al.1989).

\section{CANCROS}

Os cancros causam perdas de cerca de $20 \%$ durante a primeira estação em plantações estabelecidas com estacas de Álamo não enraizadas. Os cancros são mais severos em solos pobres e sob condições ambientais de estresse. Septoria musiva é considerado o organismo pioneiro. Fusarium solani, Cytospora chrysosperma, Phomopsis macrospora e Botryodiplodia theobromae 
usualmente invadem os pequenos cancros de Septoria. Contudo, esses fungos são secundários na sucessão ecológica, podendo isolada ou coletivamente causar a mortalidade da planta.

II.1 CANCRO DE SEPTORIA - Septoria musiva: cancros enfraquecem galhos e tronco, permitindo a colonização por organismos secundários e quando circundam a árvore podem causar morte da árvore. Os sintomas são áreas deprimidas nos galhos e troncos com aparência encharcada. Corpos de frutificação do patógeno normalmente são encontrados no primeiro ano do desenvolvimento do cancro. $\mathrm{O}$ fungo sobrevive no inverno em folhas infectadas caídas e em cancros jovens. Na primavera, os ascósporos das folhas podem ser depositados em folhas, troncos e galhos, ocorrendo novas infecções. As infecções secundárias ocorrem durante o verão por meio dos conídios produzidos nas manchas foliares. O controle indicado é a remoção de folhas em decomposição antes da liberação dos esporos na primavera para reduzir o inóculo inicial; clones resistentes e viveiro livre do patógeno.

II.2 CANCRO DE HIPOXYLON - Hipoxylon mammatum: o fungo circunda e mata hastes e galhos. Árvores pequenas podem ser mortas em 2 a 4 anos. Cancros jovens são levemente afundados, com áreas amarelo-alaranjadas na casca dos galhos, freqüentemente associados a ferimentos de insetos. Cancros em estádio mais avançado apresentam esporos sexuais (ascósporos) em estruturas escuras lembrando almofadas na superfície do cancro. O patógeno sobrevive em cancros. Árvores mortas permanecem como fonte de inóculo por muitos anos.

\section{II.3 NECROSE DO TRONCO, MORTE DE PONTEIRO, HASTE} NEGRA - Cytospora, Phomopsis, Dothichiza: os patógenos podem provocar danos ou morte de estacas logo após o plantio. Os sintomas são cancros levemente deprimidos com margem definida ou parte descolorida do galho ou haste. Os tecidos infectados podem ser amarelos, alaranjados, amarronzados ou negros, contrastando com a coloração verde normal. Os sintomas produzidos por estes fungos se confundem, para diferenciá-los deve-se examinar as estruturas reprodutivas em meios de cultivo artificiais. Infectam normalmente plantas mortas ou debilitadas por seca, ataque de insetos, escaldadura do sol, geada e desbalanço nutricional. Como controle recomenda-se minimizar ao máximo as condições de estresse da planta, principalmente durante o plantio .

II.4 OUTROS CANCROS: além dos patógenos já citados, outros fungos tais como Fusarium, Nectria, Ceratocystis, Cryptosphaeria, Phibalis podem ocasionar cancros em álamo. Os sintomas são áreas de descoloração e depressão na casca com rachaduras irregulares e áreas deformadas e inchadas nos ramos. Geralmente os patógenos penetram na planta por meio de 
ferimentos. Os cancros podem ser agrupados em três categorias: anual, como por exemplo o de Fusarium, no qual o crescimento fúngico é paralisado por um calo após o primeiro ano; perene, como o caso de Ceratocystis e Nectria, que escapam do calo e avançam a cada ano. A categoria difusa cujos representantes são fungos como Phibalis e Cryptosphaeria formam cancros grandes normalmente sem calos. O principal controle é evitar ferimentos nas árvores (OSTRY et al.1989).

II.5 CANCRO BACTERIANO - Xanthomonas populi: nos galhos ou em pequenos ramos aparecem deformações semelhantes a bolhas, enegrecidas e rachadas. A casca apresenta áreas deprimidas que exsudam pus bacteriano branco durante períodos de alta umidade. A bactéria dissemina-se por gotas de água, ferramentas, insetos e animais. A infecção ocorre por ferimentos sendo sua extensão dependente da suscetibilidade do clone. Como controle é indicado a escolha de clones resistentes.

\section{DOENÇAS DO COLO E RAIZ}

III.1 PODRIDÃO DE RAIZ DE ARMILARIA - Armilaria mellea: os sintomas são observados em reboleira, resultante do crescimento do patógeno no solo e da propagação da doença de planta a planta ou raiz a raiz. As árvores inicialmente exibem crescimento vagaroso, as folhas tornam-se amarelecidas e caem. Há seca de ponteiros e finalmente morte das plantas. Nas imediações do colo observam-se placas miceliais brancas de bordas dendríticas, que se desenvolvem entre a casca e o lenho.

A. mellea é um fungo parasita facultativo, que sobrevive saprofiticamente em troncos, tocos e raízes em decomposição. Desses substratos, os rizomorfos e as hifas espalham-se pelo solo. O fungo pode penetrar as raízes por ferimentos. A partir dessas raízes, a colonização prossegue, podendo chegar até o coleto da árvore, anelando-a. Ramificações rizomórficas ou de hifas podem também atingir outras raízes, levando a planta à morte.

Como medidas de controle recomendam-se: recolher restos de raízes, tocos, troncos e galhos da área e queimá-los, com o objetivo de reduzir o inóculo. Além disso sugere-se a abertura de trincheiras ou valas, separando árvores atacadas das sadias (TARIS ,s/d).

III.2 PODRIDÃO DE RAIZ DE ROSELINIA - Roselinea necatrix: de modo geral, este fungo vive como saprófita sobre troncos, raízes mortas e na camada humosa do solo. Uma vez que o fungo passa a parasitar o sistema radicular das plantas cultivadas, estas passam a mostrar sintomas reflexos na parte aérea. Os sintomas apresentam-se inicialmente como uma clorose das folhas. À medida 
que o processo patológico se agrava, as mesmas revelam uma coloração amarela, secam e caem ao solo. Os galhos secam a partir das pontas até que toda a planta se apresenta seca. A duração do processo patológico pode variar de meses até anos. As raízes das plantas mostram na sua superfície cordões rizomórficos grossos e micélio de cor branca na região entre a casca e o lenho da raiz, não se estendendo para o tronco da planta (TARIS ,s/d)

Como controle recomenda-se eliminar as plantas doentes, bem como todos os restos de raízes e troncos da área.

\section{III.3 OUTRAS PODRIDÕES RADICULARES}

Fungos como Cytocibe tabescens, Corticium galactinum e Pleurotus ostreatus estão relatados como causadores de podridão radicular em álamo. Estes fungos atacam as raízes e a parte basal da haste da planta. Árvores com sistema radicular atacado mostram os sintomas característicos de desordem radicular com declínio no crescimento e, na maioria das vezes, não competem bem com as árvores adjacentes e morrem.

\section{REFERÊNCIAS BIBLIOGRÁFICAS}

ALEGRO, G.; GIORCELLI, A.; VIETTO, L. Situazione fitossanitária della pioppicultura. Celulosa e Carta, n.2, p.2-9, 1992.

CELLERINO, G.P. Evoluzione delle malattie del pioppo in Italia e strategie di lotta. Annali dell'accademia di agricoltora di torino, Torino, v.120, p.114, 1986.

COOPER, D.T.; FILER JR, T.H. Geographic variation in Melampsora rust resistance in eastern cottonwood in the lower Mississippi valley. Proccedings of the tenth Central States Forest Tree Improvement Conference 1976, p. 146-151. 1977.

GIORCELLI, A.; VIETTO, L.; ANSELMI, N.; GENNARO, M. The influence of inoculum pressure, clonal susceptibility and leaf age on Melampsora larici-populina Kleb. E1 and E3 races infections. FAO/IPC Working Party on Diseases, Izmit (Turkey), 12p., 1994.

GIORCELLI, A; VIETTO, L. Secondo biennio di prove di lotta control Marsonina brunea (Ell. et Ev.) P. Magn. con tratamenti preventivi e curativi. Linea Ecologica, n.5, p.53-57, 1992.

GIORCELLI, A; VIETTO, L. Valutatazione delléfficacia di alcunio fungicidi versu le ruggini del pioppo. Informatore Fitopatologico, v.45, n.6, p.5962, 1995./Resumo/

HAMELIN, R.C.; SHAIN, L.; THIELGES, B.A Influence of leaf wetness, temperature, and rain on poplar leaf rust epidemics. Can. J. For. Res., v.22, n.9, p.1249-1254, 1992. 
MAY-DE MIO, L.L. \& SCHUTA, L.R. Eficiência da aplicação de fungicidas no controle de Melampsora medusae e em relação ao vigor da muda de álamo. Summa Phytopathologica, v.23, n.1, p.55. 1997. /Resumo/

MAY-DE MIO, L.L. Identificação das principais doenças do Álamo (Populus spp) e Epidemiologia e Controle Químico da ferrugem (Melampsora medusae Thüm). Curitiba: FUPEF-PR, 1997. 64 p. (Relatório técnico apresentado à Fundação de Pesquisas em Florestas da Universidade Federal do Paraná)

McCRACKEN, F.I.; SCHIPPER, A. L.; WIDIN, K.D. Observation on occurrence of cottonwood leaf rust in central United States. European Journal of Forest Pathology, v.14, n.4-5, p.226-233, 1984.

NEWCOMBE, G. Association of Mmd1, a major gene for resistance to Melampsora medusae f.sp. deltoidae, with quantitative traits in poplar rust. Phytopathology, v.88, n.2, p.114-121, 1998.

NEWCOMBE, G.; CHASTAGNER, G.A. A leaf rust epidemic of hybrid poplar along the lower Columbia River caused by Melampsora medusae. Plant Disease, v.77, p.528-531, 1993.

NEWCOMBE, G.; STIRLING, B.; McDONALD, S.K.; BRADSHAW JR, H.D. Melampsora x columbiana, a natural hibbrid of M. medusae e $M$. occidentalis. Mycological Research, v.104, p.261-275, 2000.

NOWACKI, M.J.; FONTOURA, O S. Alguns aspectos fitossanitários da silvicultura no Estado do Paraná. In: Congresso Florestal Brasileiro, 1, 1968, Curitiba. Anais. Curitiba: Federação das Indústrias do Estado do Paraná - Associação Paranaense de Engenheiros Florestais, p.315 -316, 1968.

OSTRY, M.E., WILSON, L.F. McNABB Jr, H.S.; MOORE, L.M. Aguide to insect, disease, and animal pests of poplars. Agric, Handb. 677, Washington, Dc 118p. 1988.

PAILLASSA, E. Les roilles et le peuplier. Les cahiers techniques de l'objetif 1, Bulletin trimestriel n. 2, p.9-18, Centre de Populiculture du Hainaut, 1996.

PANDEY, P.C.; SINGH, A.; KARNATAK, D.C.; BHARTARI, B.K. Melampsora larici-populina on poplars in India and its control in nursery. The Indian Forester, v.122, n.11, p.1062-1067, 1996.

PINON, J.; FREY, P. Remarques relatives a la lutte contre les rouilles: la conservation du parasite sur les feuilles hibernantes, ses modalites, les risques qui en resultent et les moyens de s'en proteger. Les cahiers techniques de l'objetif 1, Bulletin trimestriel n. 1, p.3-5, Centre de Populiculture du Hainaut, 1998.

PRAKASH, C.S.; HEATHER, W.A. Effects of changing temperature regimes on resistance to races of Melampsora medusae in cultivar of poplar. Annual Appl. Biol., v.108, p.403-407, 1986b. 
PRAKASH, C.S.; THIELGES, B.A. Pathogenic variation in Melampsora medusae leaf rust of poplars. Euphytica, v.36, p. 563-570, 1987.

PRAKASH, C.S.; THIELGES, B.A. Interaction of geographic isolates of Melampsora medusae and Populus: effect of temperature. Canadian Journal of Botany, v.67, p. 486-490, 1989.

RUARO, L.; MAY, L.L. Caracterização da ferrugem do álamo (Populus spp.) e eficiência de fungicidas in vitro na germinação de uredosporos. Revista do Setor de Ciências Agrárias, Curitiba, v.15, n.1, p.77-82, 1996.

SHAIN, L. A search for aecial hosts of Melampsora medusae among some conifers grown in the eastern United States. Plant Disease, v.72, n.10, p.904-906, 1988a.

SHAIN, L. Evidence for forma speciales in the poplar leaf rust fungus, Melampsora medusae. Mycologia, v.80, p.729-732, 1988b.

SHAIN, L.; CORNELIUS, P. I. Quantitative inoculation of eastern cottonwwod leaf tissue with Melampsora medusae under controlled conditions. Phytopathology, St. Paul, v.69, n.3, p.301-304, 1979.

SHERIDAN, J.E. Poplar leaf rust and its effect on tree growth and suitability for match splints. Wellington, 1981. 25p.

SHERIDAN, J.E.; HARPER, J.E.; STEVENSON, G. Note on epidemiology and control of poplar leaf rust. N. Z. Journal Science, v.18, p.211-216, 1975.

SINGH, S.J.; HEATHER, W.A Temperature sensitivity of qualitative racecultivar interactions in Melampsora medusae THUM. And Populus species. Eur. J.For.Path., v.12, p.123-127, 1982.

SPIERS, A.G. Species of Melampsora infecting conifers in New Zeland. Plant Disease Reporter, v.59, n.6, p.486-488, 1975.

SPIERS, A. G.; HOPCROFT, D.H. Comparative studies of the poplar rusts Melampsora medusae, M. larici-populina and their interspecific hybrid M. medusae-populina. Mycological Research, v.98, n.8, p.889-903, 1994. (Resumo)

STEENACHERS, J.; STEENACHERS M.; STEENACHERS, V. Maladies des peupliers - Consequences sur la croissance et la qualite du bois. Les cahiers techniques de l'objetif 1, Bulletin trimestriel n. 1, p.4-20, Centre de Populiculture du Hainaut, 1995.

STEENACHERS, M.; STEENACHERS, V.; DELPORTE, T. A new physiological race of Melampsora larici-populina in belgium. FAO-CIP Meetings of the working group of Diseases, 6p., Turkey, outubro, 1994.

TARIS, B. (Coord.) Les Maladies des peupliers. Groupe de Travail des Maladies de la Commission Internationale du Peuplier (sem data)

TOOLE, E.R. Melampsora medusae causes cottonwood rust in lower Mississippi valley. Phytopathology, v.57, p.1361-1362, 1967. 
TRENCH, T.N.; BAXTER, A.P.; CHURCHILL, H. First report of Melampsora medusae on Populus deltoides in Africa. South African Forestry Journal, n.144, p.6-9, 1988.

VIÉGAS, A.P. Alguns fungos do Brasil. IV. Uredinales. Bragantia, Campinas, v.5, n.1, p.6-7, 1945.

WALKER, J. Melampsora medusae. CMI Descriptions of Patogenic Fungi and Bacteria, $n^{\circ}$ 480. Commonwealth Mycological Institute, Kew, 2p., 1975.

WIDIN, K.D.; SCHIPPER JR., A.L. Epidemiology and impact of Melampsora medusae leaf rust on hybrid poplars. In: Intensive plantation culture five year's research. U.S. For. Serv. Gen. Tech. Rep. NC-21. U.S. Dep. Agric. For. Serv., North Cent. For. Exp. Stn., St. Paul, MN, p.63-74, 1976.

WILCOX, J.R. \& FARMER, R.E.J. Variation and inheritance of juvenile characters of eastern cottonwood. Silvae Genetic, v.16, p.162-165, 1967.

ZILLER, W.G. Studies of western tree rust. VI The aecial host ranges of Melampsora albertensis, M. medusae, and M. occidentalis. Canadian Journal of Botany, v.43, p. 217-230, 1965.

ZILLER, W.G. Tree rust of western Canada. Can. For. Serv., n.1329, Victoria, B.C., 1974. 